\title{
Combating plastic waste via Trash to Tank
}

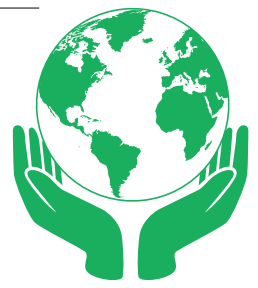

\section{Chandni Joshi, Shelby Browning and Jeffrey Seay}

Due to lack of infrastructure and capital to manage waste properly, developing regions face significant challenges from plastic waste accumulation. The Trash-to-Tank program enables communities to locally convert post-consumer use plastic to plastic-derived fuel oil, providing environmental and economic benefits. ability of pre-packaged goods have led to increased usage of plastic. This explosion of consumption coupled with low degradability have led to significant plastic accumulation in the environment, negatively impacting ecosystems and human health. Challenges associated with plastic waste are especially acute in developing countries, where capital and infrastructure constraints, lax regulation and lack of waste management education have led to plastic being discarded in unregulated dumps, open plots of land, streets and waterways. Addressing this problem requires locally
Population growth, urbanization and avail-

managed, decentralized solutions to empower communities to combat plastic waste.

Trash-to-Tank (3T) - developed at the University of Kentucky Appropriate Technology and Sustainability (UKATS) research lab - offers a solution to plastic pollution. This process uses thermal decomposition to convert polyolefin plastic into plastic-derived fuel oil (PDFO), which is a sulfur-free substitute for traditional diesel fuel. The 3T processor is small (about the size of an oil drum), simple to use and costs less than 1,000 USD, making it ideal for developing countries. By operating the 3T processor 5 times per week, 20-25litres of

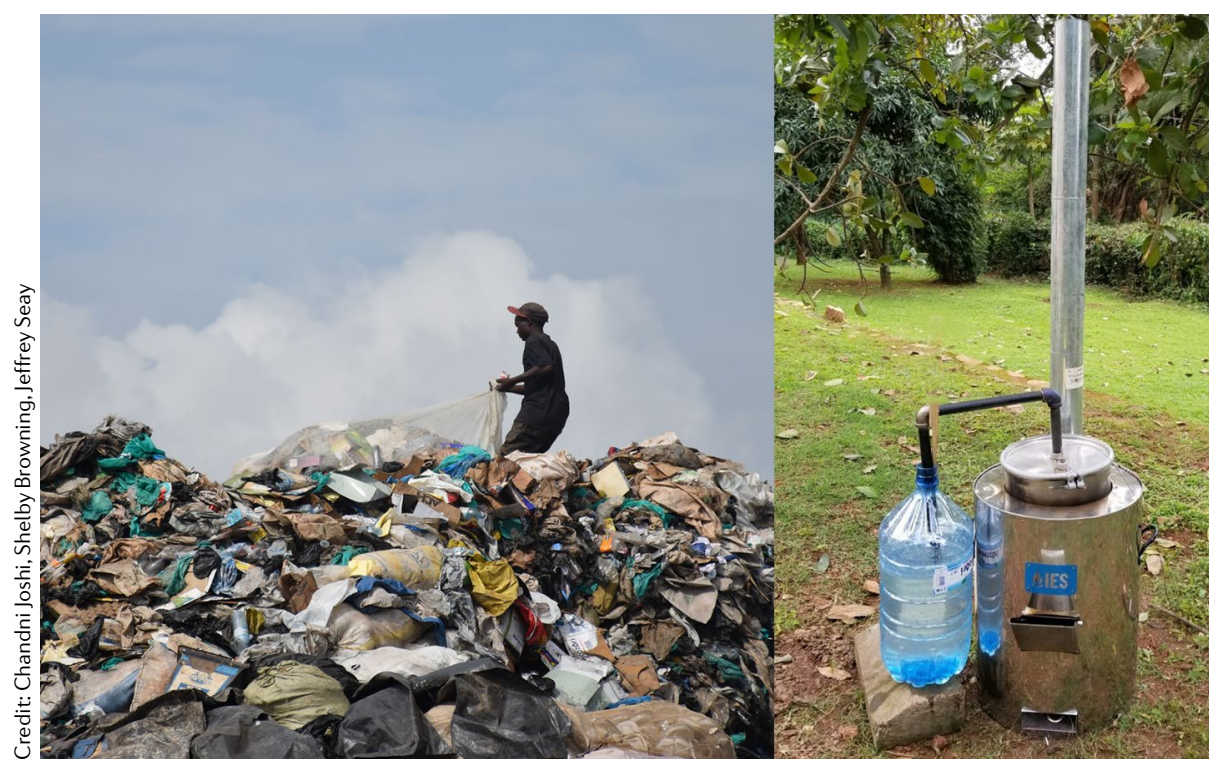

PDFO can be produced from 20-25 kilograms of plastic, a saving that can quickly limit waste.

The 3T process further provides entrepreneurial opportunities to individuals. As local raw material is converted into a product that can be sold and used nearby, the social and economic benefits are realized locally. While it is possible to support a family on profits from PDFO sales (operators can make over 150\% profit on the sale of PDFO), it is currently regarded as a form of supplemental income until a PDFO market has been developed. By giving an economic value to a product currently seen as trash, the $3 \mathrm{~T}$ process has provided a roadmap for sustainable management of post-consumer plastic in developing communities.

Since 2017, UKATS has implemented six $3 \mathrm{~T}$ processors in Uganda in partnership with Makerere University and Beyond Uganda (a USA-based NGO) as a pilot program. Local response has been overwhelmingly positive, with entrepreneurs curious and excited to try the process for themselves. Ongoing monitoring and development will lead to a model for implementation in other underdeveloped countries. Plans are currently underway to implement the project in Central America, while continuing the case studies in Uganda.

Chandni Joshi, Shelby Browning and Jeffrey Seay $\bowtie$ College of Engineering, University of Kentucky, Paducah, KY, USA

凶e-mail: jeffrey.seay@uky.edu https://doi.org/10.1038/s43017-020-0032-3

Competing interests

The authors declare no competing interests. 